ISSN: $0344-2340$

clis N: $1984-1641$

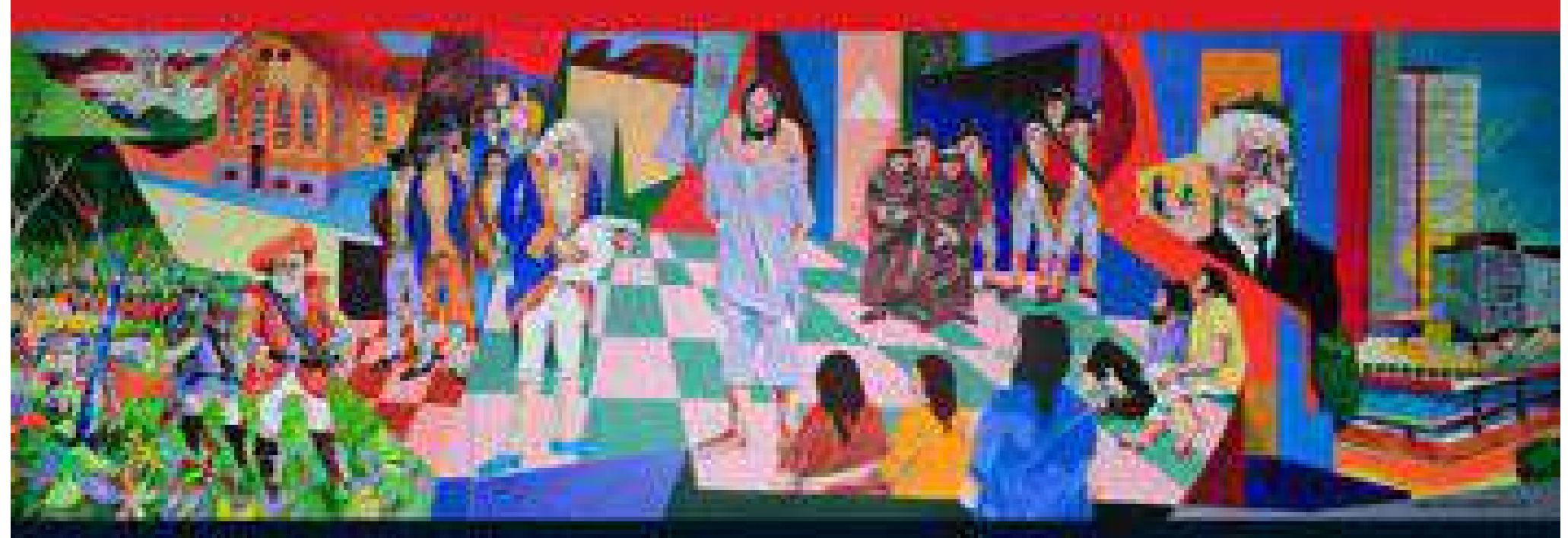

REVITA DA FACULDADE DE

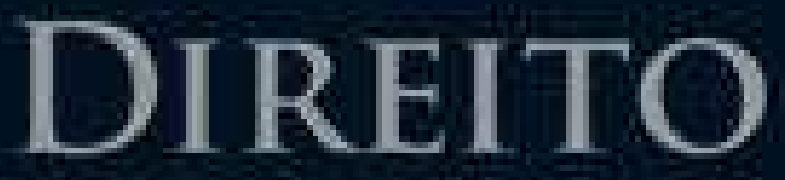

DUSAE

HBIOGA DO DIREIIO MIEM DAS FRONIEIMAS, CIRC ULWCLO INIEENMCIONAI DO DIREITO NA MODERNIDADE

SPCLI INUT:

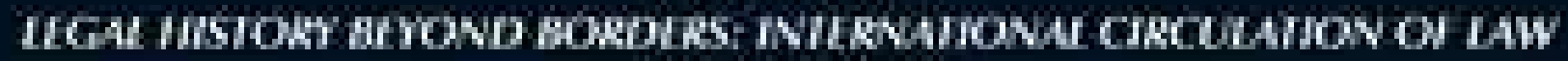

N Movikwir

n. 74 , jan./un. 2019

UNIVERSIDADE FEDERAL. DE MINAS GERAIS. 


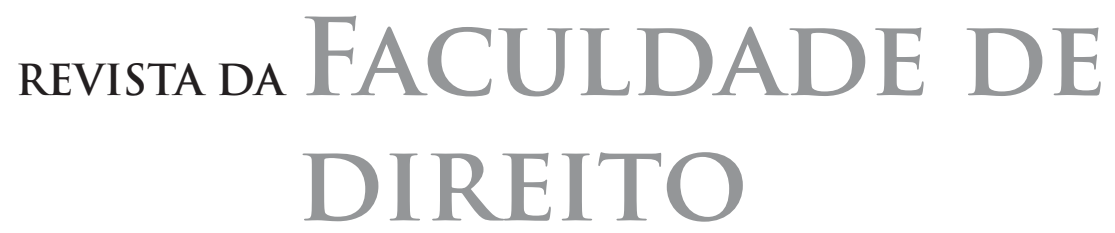




\section{UNIVERSIDADE FEDERAL DE MINAS GERAIS}

\section{revista da FACULDADE DE DIREITO}

DOSSIÊ
HISTÓRIA DO DIREITO ALÉM DAS FRONTEIRAS: CIRCULAÇÃO INTERNACIONAL DO DIREITO NA MODERNIDADE

SPECIAL ISSUE

LEGAL HISTORY BEYOND BORDERS: INTERNATIONAL CIRCULATION OF LAW IN MODERNITY

ISSN: $0304-2340$

e-ISSN: $1984-1841$ 


\section{(C) 2019 Revista da Faculdade de Direito da UFMC}

Printed in Brazil

Qualquer parte desta publicação pode ser reproduzida, desde que citada a fonte.

As opiniões emitidas em artigos ou notas assinadas são de exclusiva responsabilidade dos respectivos autores.

Esta revista encontra-se disponível também em http://www.direito.ufmg.br/revista

DOI:

Pede-se permuta

Pídese canje

Man bittet um Austausch

We ask for Exchange

On demande l'échange

Si riquiere lo scambio

Esta publicação encontra-se indexada nas seguintes bases de dados: Ulrich's Periodical Directory, Bibliotheksservice-Zentrum Baden-Württemberg, ZBD: Zeitschriftendatenbank, e Latindex, dentre outras.

Revista da Faculdade de Direito da Universidade Federal de Minas Gerais.

Nova Fase - 1962. - Belo Horizonte.

Títulos anteriores: Revista da Faculdade Livre de Direito do Estado de Minas Gerais, 1894 - 1928; Revista da Faculdade de Direito da Universidade de Minas Gerais, 1929 - 1948; Revista da Faculdade de Direito da Universidade Federal de Minas Gerais, 1949 - 1961; Revista da Faculdade de Direito da Universidade Federal de Minas Gerais - Nova Fase, 1962.

ISSN: $0304-2340$

E-ISSN: $1984-1841$

Periodicidade: semestral

1 - Direito - Periódicos - Faculdade de Direito da UFMG

CDU - $34(05)$

CDU - 340-05

Foto da Capa: Foca Lisboa - Painel de Jarbas Juarez, 1997 - Auditório da Faculdade de Direito da UFMC Projeto Gráfico, Formatação e Capa: Júnior Sena

Impressão: Imprensa Universitária da UFMG

Tiragem: 120 exemplares

Valor, nesta data, por unidade R\$30,00

Os números atrasados da Revista da Faculdade poderão ser solicitados no endereço abaixo:

\section{FACULDADE DE DIREITO DA UFMC}

Revista da Faculdade

Av. João Pinheiro, 100 - 15o andar, sala 1507 / 1508

CEP 30130-180 - Belo Horizonte - MG - Brasil

Tel.: + 5531 3409-8651

http://www.direito.ufmg.br/revista

revista@direito.ufmg.br 


\section{REVISTA DA FACULDADE DE DIREITO UNIVERSIDADE FEDERAL DE MINAS GERAIS \\ (Fundada em 1894)}

Palavras do Conselheiro Affonso Penna no lançamento da Revista da Faculdade de Direito:

"Encetando a publicação de sua Revista, vem a Faculdade Livre de Ciências Jurídicas e Sociais da capital do Estado de Minas Gerais contribuir com o seu modesto auxílio para o estudo do Direito, pedra angular sobre que repousam as sociedades humanas."

REITORA DA UFMG

Prof ${ }^{a}$. Dr ${ }^{a}$. Sandra Regina Goulart Almeida

VICE-REITOR DA UFMG

Prof. Dr. Alessandro Fernandes Moreira

DIRETOR DA FACULDADE DE DIREITO DA UFMG

Prof. Dr. Hermes Vilchez Guerrero

DIRETOR-EDITOR

Prof. Dr. Edson Kiyoshi Nacata Junior

DIRETORA-ADJUNTA

Prof ${ }^{a}$. Dr ${ }^{a}$. Jamile Bergamaschine Mata Diz

ASSESSORA EDITORIAL

Rosali Ramos Diniz

ASSISTENTE EDITORIAL

Luisa Côrtes Grego

Mariana Barcelos Faria

CONSELHO EDITORIAL

Prof. Dr. Alejandro Montiel Alvarez (Universidade Federal do Rio Grande do Sul - Porto Alegre, MG - Brasil) Prof. Dr. Alessandro Hirata (Faculdade de Direito da USP - Ribeirão Preto, SP - Brasil)

Prof. Dr. Andrew Drzemczewski (Conselho da Europa - Strasbourg, Alsace - France)

Prof. Dr. Antônio Augusto Cançado Trindade (Universidade de Brasília - Brasília, DF - Brasil)

Prof. Dr. Bjarne Melkevik (Université Laval - Quebéc, Quebéc - Canadá)

Prof ${ }^{a}$. Dr ${ }^{a}$. Daniela de Freitas Marques (Universidade Federal de Minas Gerais - Belo Horizonte, MG - Brasil)

Prof. Dr. Dean Spielmann (University of Luxembourg - Walferdange, Luxembourg - Luxembourg)

Profa. Dr ${ }^{a}$. Elena Lisanyuk (State University of Saint Petersburg - Saint Petersburg, Northwestern - Russia)

Prof ${ }^{a}$. Dr ${ }^{a}$. Fabiana de Menezes Soares (Universidade Federal de Minas Gerais - Belo Horizonte, MG - Brasil)

Prof. Dr. Georges Abboud (Pontifícia Universidade Católica de São Paulo, São Paulo - Brasil)

Prof. Dr. Germain Ngoie Tshibambe (Université de Lubumbashi - Lubumbashi, Katanga - República Democrática do

Congo)

Prof. Dr. Giovani Clark (Universidade Federal de Minas Gerais - Belo Horizonte, MG - Brasil)

Prof. Dr. Gustavo Silveira Siqueira (Universidade do Estado do Rio de Janeiro - Rio de Janeiro, RJ - Brasil)

Prof. Dr. Héctor Fix Zamúdio (Universidad Nacional Autónoma de México - Ciudad de Mexico, DF - Mexico)

Prof. Dr. Hugo Llanos Mansilla (Universidad Católica de Chile - Santiago - Chile)

Prof. Dr. Jean Paul Cabral Veiga da Rocha (Universidade de São Paulo - São Paulo, SP - Brasil)

Prof. Dr. João Maurício Leitão Adeodato (Universidade Federal de Pernambuco - Recife, PE - Brasil)

Prof ${ }^{a}$. Dr ${ }^{a}$. Juliana Neuenschwander Magalhães (Universidade Federal do Rio de Janeiro - Rio de Janeiro, RJ - Brasil)

Prof. Dr. Juan Ramón Capella Hernandez (Universidad de Barcelona - Barcelona, Cataluña - Espanha)

Prof ${ }^{a}$. Dr ${ }^{a}$. Lorena Ossio Bustillos (Max-Planck - Institute and German University of Administrative Sciences - Speyer,

Rheinland-Pfalz - Alemanha)

Prof. Dr. Mikhail Antonov (Law Faculty of National Research University "Higher School of Economics" - Saint

Petersburg, Northwestern - Russia)

Prof $^{a}$. Dr ${ }^{a}$. Miracy Barbosa de Sousa Gustin (Universidade Federal de Minas Gerais - Belo Horizonte, MG - Brasil)

Prof ${ }^{a}$. Dr ${ }^{a}$. Misabel de Abreu Machado Derzi (Universidade Federal de Minas Gerais - Belo Horizonte, MG - Brasil)

Prof ${ }^{a}$. Dr ${ }^{a}$. Mônica Sette Lopes (Universidade Federal de Minas Gerais - Belo Horizonte, MG - Brasil)

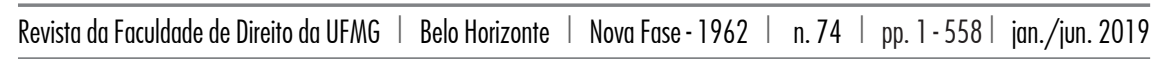


Prof ${ }^{a}$. Dr ${ }^{a}$. Natasha Schmitt Cáccia Salinas (Universidade Federal de São Paulo - São Paulo, SP - Brasil)

Prof. Dr. Nuno Manuel Morgadinho dos Santos Coelho (Universidade de São Paulo - Ribeirão Preto, SP - Brasil)

Prof. Dr. Pierre Issalys (Université Laval, Canadá - Quebéc, Quebéc - Canadá)

Prof. Dr. Ricardo Antônio Lucas Camargo (Universidade Federal do Rio Grande do Sul - Porto Alegre, RS - Brasil)

Prof. Dr. Roberto Luiz Silva (Universidade Federal de Minas Gerais - Belo Horizonte, MG - Brasil)

Prof ${ }^{a}$. Dr ${ }^{a}$. Suzy Elizabeth Cavalcante Koury (Centro Universitário do Estado do Pará - Belém, PA - Brasil)

Prof. Dr. Stephan Kirste (Universität Salzburg ᄀ- Salzburg, Salzburg - Áustria)

Prof. Dr. Tércio Sampaio Ferraz Júnior (Universidade de São Paulo - São Paulo, SP - Brasil)

\section{CONSELHO DE PARECERISTAS AD HOC}

Prof. Dr. Alfredo de Jesus Dal Molin Flores (Universidade Federal do Rio Grande do Sul - Porto Alegre, RS - Brasil)

Prof. Dr. António Manuel Hespanha (Universidade de Nova Lisboa - Lisboa - Portugal)

Prof. Dr. Bernardo Sordi (Università degli Studi Firenze - Firenze - Itália)

Prof. Dr. Carlos Petit (Universidad de Huelva - Huelva - Espanha)

Profa. Dra. Claudia Storti (Università degli Studi de Milano - Milano - Itália)

Profa. Dra. Cristina Nogueira da Silva (Universidade de Nova Lisboa - Lisboa-Portugal)

Prof. Dr. Dave De ruysscher (Tilburg University - Tilbug - Holanda)

Prof. Dr. Diego Nunes (Universidade Federal de Santa Catarina - Florianópolis, SC - Brasil)

Prof. Dr. Edson Kiyoshi Nacata Junior (Universidade Federal de Minas Gerais - Belo Horizonte, MG - Brasil)

Prof. Dr. Georges Martyn (Ghent University - Ghent - Bélgica)

Prof. Dr. Giordano Bruno Soares Roberto (Universidade Federal de Minas Gerais - Belo Horizonte, MG - Brasil)

Prof. Dr. Guido Rossi (The University of Edinburgh - Edinburgh - Escócia)

Prof. Dr. Ivan de A. Vellasco (Universidade Federal de São João Del Rey - São João Del Rey, MG - Brasil)

Prof. Dr. Jean-Louis Halperin (École Normale Supérièure de Paris - Paris - França)

Profa. Dra. Laura Beck Varela (Universidad Autónoma de Madrid - Madrid - Espanha)

Prof. Dr. Luigi Lacchè (Università degli Studi di Macerata - Macerata - Itália)

Prof. Dr. Luís Fernando Lopes Pereira (Universidade Federal do Paraná - Curitiba, PR - Brasil)

Prof. Dr. Marcelo Casseb Continentino (Universidade de Pernambuco - Recife, PE - Brasil)

Prof. Dr. Marco Nicola Miletti (Università degli Studi di Foggia - Foggia - Itália)

Prof. Dr. Marcos Luiz Bretas (Universidade Federal do Rio de Janeiro - Rio de Janeiro, RJ - Brasil)

Prof. Dr. Massimo Meccarelli (Università degli Studi di Macerata - Macerata - Itália)

Prof. Dr. Michele Pifferi (Università degli Studi di Ferrara - Ferrara - Itália)

Prof. Dr. Osvaldo Barreneche (Universidad Nacional de La Plata/CONICET - La Plata-Argentina)

Prof. Dr. Paolo Marchetti (Università degli Studi di Teramo - Teramo - Itália)

Prof. Dr. Pietro Costa (Università degli Studi di Firenze - Firenze - Itália)

Prof. Dr. Rafael Mafei Rabelo Queiroz (Universidade de São Paulo - São Paulo, SP - Brasil)

Prof. Dr. Ramón Pedri Yanzi Ferreira (Universidad Nacional de Córdoba - Córdoba - Argentina)

Prof. Dr. Samuel Barbosa (Universidade de São Paulo - São Paulo, SP - Brasil)

Prof. Dr. Sebastián Martín (Universidad de Sevilla - Sevilla - Espanha)

Prof. Dr. Stephen Skinner (University of Exeter - Exeter - Inglaterra)

Prof. Dr. Thiago Reis (Fundação Getúlio Vargas - São Paulo, SP - Brasil) 


\title{
VOYAGE EN ITALIE. CODE NAPOLEON E HISTORIOGRAFIA: UM ESBOÇO INACABADO*
}

\section{VOYAGE EN ITALIE. CODENAPOLEONAND HISTORIOGRAPHY: AN UNFINISHED ESSAY}

\author{
PAOLO CAPPELLINI**
}

\section{RESUMO}

Este ensaio pretende propor uma releitura historiográfica crítica das relações entre o código civil napoleônico de 1804 e a cultura jurídica italiana oitocentista a partir de um ponto de vista liberto das narrativas liberais e iluministas fundadas na noção de progresso. Tal observatório permite perceber o impacto do código napoleônico na própria língua italiana, a palavra 'modelar-se' [modellarsi] vinculada ao código francês, e a própria ideia de modelo como uma espécie de obstáculo epistemológico no debate jurídico italiano do século XIX sobre codificação.

PALAVRAS-CHAVE: História do Direito. História das codificações. Código Napoleão. Codificação na Itália.

\begin{abstract}
The purpose of this essay is to propose a historiographical reinterpretation of the relationships between the 1804 Napoleonic civil code and the Italian legal culture of the 19th century from a point of view released from the liberal and iluminists narratives based on the progress idea. Such point of view allows us to perceive the impact of the Napoleonic code over the Italian language itself, the word modellarsi bonded to the French code, and the own idea of a model as a kind of epistemological obstacle within the Italian legal debate of the 19th century on codification.
\end{abstract}

KEYWORDS: Legal History. History of codification. Napoleonic code. Codification in Italy.

"Parrebbe ora affatto miracoloso questo Codice d'un centinaio di pagine che pon ordine a tante materie così disparate"

(Ippolito Nievo).

1.

As obras e eventos históricos, para viver e esculpir-se na memória, precisam da palavra e (da escrita) da história. Ou melhor, poderíamos dizer que, de certa maneira, fazem a língua e a historiografia: tornam-se língua nova e procuram para si uma história própria. Não necessariamente sempre a mesma.

* Viaggio in Italia. Code Napoléon e storiografia: uno schizzo incompiuto", publicado originalmente em: 'Iuris Quidditas'. Liber amicorum per Bernardo Santalucia. Napoli: Editoriale Scientifica, 2010. Tradução da língua italiana por Ricardo Sontag.

* Professor catedrático de História do Direito Medieval e Moderno na Università degli Studi di Firenze (UNIFI). Diretor do Centro di Studi per la Storia del Pensiero Giuridico Moderno (UNIFI). Email: paolo.cappellini(AT)unifi.it 
De fato, talvez todos os eventos decisivos transcendem, por assim dizer, a pura historicidade, para ambicionar algo mais, diferente.

Em suma, para tais eventos, vale, a nosso ver, o que Roland Barthes afirmava em Critique et Vérité (1966) - ainda que agora possa parecer superado, para alguns, o eco dos tempos em que em que tais reclames pareciam obrigatórios - a proposito da obra (literária?):

Chaque époque peut croire, en effet, qu'elle détient le sens canonique de l'oeuvre, mais il suffit d'élargir un peu l'histoire pour transformer ce sens singulier en sens pluriel et l'oeuvre fermée en oeuvre ouverte. La définition meme de l'oeuvre change: elle n'est plus un fait historique, elle devient un fait anthropologique, puisque aucune histoire ne l'épuise. La variété des sens ne rèleve donc pas d'une vue relativiste sur le moeurs humaines: elle désigne, non un pechant de la société à l'erreur, mais une disposition de l'oeuvre à l'ouverture; l'oeuvre détient en meme temps plusiers sens, par structure, non par infirmité de ceux qui la lisent. C'est en cela qu'elle est symbolique: le symbole, ce n'est pas l'image, c'est la pluralité meme des sens ${ }^{1}$.

Mas não é somente este o ponto; e o leitor há de nos perdoar se, para alcançar o nosso primeiro objetivo, não resistimos mais uma vez ao fascínio da palavra branca barthesiana:

Le symbole est constant. Seuls peuvent varier la conscience que la société en a et les droits qu'elle lui accorde. La liberté symbolique a été reconnue et en quelque sorte codée, au Moyen Age, comme on le voit dans la théorie des quatre sens (littéral, allégorique, moral et anagogique. Il subsiste évidemment une traversée orientée des sens vers le sens anagogique); en revanche, la société classique s'en est gèneralement fort mal accomodée: elle l'a ignorée, ou, comme dans ses survivances actuelles, censurée: c'est une histoire souvent violent que celle de la liberté des symboles, et naturellement ceci a également son sens: on ne censure pas impunément les symboles"2.

Aqui, uma pequena pausa na tessitura do texto para recolher alguns cacos necessários: a ignorância voluntária, a censura do símbolo na modernidade, por um lado (que se repete na negação de reconhecer, mesmo quando lhe são indicados, os "mitos de hoje"); a história violenta e dos símbolos para que se libertem e dos mitos modernos (negados pela remoção) para que imponham.

Quoi qu'il soit, c'est là un problème institutionnel, et non pas, si l'on peut dire, structural: quoi que les sociétés pensent ou décrètent, l'oeuvre les dépasse, les traverse, à la façon d'une forme que des sens plus ou moins contigents, historiques, viennent remplir tour à tour: une oeuvre est 'étternelle', non parce qu'elle impose un sens unique à des hommes différents, mais parce qu'elle suggére des sens différents à un homme unique, qui parle toujours la meme langue symbolique à travers des temps multiples: l'oeuvre propose, l'homme dispose. Tout lecteur sait cela, s'il veut bien ne pas se laisser intimider par le censures de la letttre: ne sent-il pas qu'il reprend contact avec un certain

1 R. BARTHES, Critique et vérité, Paris, 1966, p. 50.

2 R. BARTHES, Critique et vérité, cit., pp. 51-52. 
au-delà du texte, comme si le langage premier de l'oeuvre développait en lui d'autres mots et lui apprenait à parler une seconde langue?" 3 .

Vejamos, agora, dois exemplos - em nossa opinião, somente primeiros passos em sendas ainda largamente a explorar - de como o mito do código, da sua escritura stendhalianamente inspiradora, nos seus diferentes sentidos e na relação nada fácil com o seu "au-delà du texte" - contribuiu na feitura da nova língua italiana, por um lado; e, de outro, prestou contas de maneira singular com uma velha tradição cultural-linguística, sabendo torcê-la, em parte, a seu favor, de maneira, exatamente, 'simbólica'.

$\mathrm{O}$ aceno a Stendhal não era puramente casual: talvez porque o 'Napoleão escritor', a inovação linguística decisiva para a instauração do culto da loi e da "généralité comme mode de régulation" - como bem enfatizou, recentemente, Pierre Rosanvallon, em Le modèle politique français. La société civile contre le jacobinisme de 1789 à nos jours (2004), inerente à técnica codificatória - é, exatamente, um dos elementos míticos que se destacam no não dito do "au-delà du texte" que diversas leituras historiográficas arrastam atrás de si.

Não por acaso, "Napoleone scrittore” (1983) é o título de um breve ensaio (agora, afortunadamente, de novo acessível) tão delicioso quanto instrutivo de um dos literatos mais stendhalianos (juntamente, como ele próprio reconhece, a Tommasi di Lampedusa e Alberto Savinio) que a Itália já conheceu: Leonardo Sciascia.

Muito poderia ser desenvolvido - e, ousamos pensar, com bons frutos também para a historiografia (não por acaso já se encontra algo em Georges Lefebvre) - a respeito do jogo de espelhos que faz Sciascia conjecturar e a se perguntar:

Nascido em 15 de agosto de 1737 teria sido, como na fantasia de Bénet, um pobre oficial de artilharia enviado para aposentadoria como major, desiludido e maníaco; nascido em 15 de agosto de 1769, tornou-se Napoleão, o grande, Imperador dos franceses. Teria se tornado escritor se tivesse nascido em 23 de janeiro de 1783 ?.

E também a se responder: "Então: por inadvertida advertência, fixamos uma data precisa para o nascimento de um Napoleão escritor. É a data de nascimento de Stendhal (...). Portanto, não temos dúvida: ele teria sido um escritor do tipo de Stendhal. Teria sido Stendhal".

Aquele Stendhal que também - é sempre Sciascia quem nos lembra -, sem desconhecer a singularidade do caráter, criticava o seu estilo e os italianismos; na crítica, mas, sobretudo, na admiração paradoxalmente próxima ao "grande, fascinado inimigo de Bonaparte": o visconde de Chateaubriand que, entusiasticamente, para além de qualquer dura reserva, podia afirmar que, no

3 R. BARTHES, Critique et vérité, cit., p. 52. 
final das contas, não importava nada que ele, meio estrangeiro, ignorasse as regras fundamentais da língua francesa, ou que, no fim, o seu discurso fosse incorreto, já que 'ele dava a palavra de ordem ao universo'. Não estamos longe de Sainte-Beuve que - depois de ter notado como, quando vivo, a ação obscurecia tudo - continuava sublinhando que a distância da ação permitia ler a palavra que resta projetando, com a memória daquela ação, um reflexo, quase um raio; e identificar, assim, a qualidade peculiar, como o seu ser, na escritura, 'a própria simplicidade'.

Também não estamos longe do nosso Savinio, 'admirador de Stendhal, mas depreciador de Napoleão', que, com acuidade, identificava uma nuance fundamental: "E quando não escreve, propõe-se a escrever, como na proclamação aos soldados depois de Waterloo: 'se me permiti sobreviver, é para servir ainda à vossa glória. Escreverei as grandes coisas que realizamos juntos”. E quando ele próprio não escreve, ele faz os outros escreverem... Em uma confissão sincera dos seus desejos recônditos, Napoleão teria trocado Arcole, Wagram, Austerlitz, por uma obra literária que desafiasse os séculos, comparável a dos grandes autores que ele tanto amava. Não há água o bastante no Rodano para lavar o literato das suas culpas: das suas invejadas culpas”.

Em última análise, talvez não só a literatura, mas também a historiografia, ou ao menos uma parte dela ${ }^{4}$, continuamente contribuem para resgatar, tendo lido, em um dos sentidos possíveis, essa paixão pela escrita 'atrás' dos secos textos jurídicos, o autor por trás do seu 'grande livro', o Código com C maiúsculo. Será essa também uma culpa? Não nos resta outra coisa senão seguir alguns fios desse percurso na terra de Sciascia e Savinio.

O primeiro diz respeito, como já mencionado, ao modo como, a partir de uma específica 'leitura', que é, precisamente, uma interpretação historiográfica, o código-grande-obra consegue introduzir uma inovação destinada a estabilizarse na língua italiana.

Vamos nos basear, no inicio da nossa viagem, em uma fonte que até agora permaneceu 'escondida' da atenção dos historiadores gerais e da totalidade dos historiadores-juristas em particular.

Trata-se do verbete Código contido, não por acaso, no Dizionario politico popolare, impresso em Torino pela associação Libera Propaganda em 1851, com os fins - visto o clima particular dos anos que se seguiram às revoluções de 1848 -, ao mesmo tempo, de educação e de propaganda próprios de uma ala progressista que procura, com a inauguração do filão de literatura para o 'povo', de maneira elitista e paternalista configurada como 'gigante-eternamente-

4 Penso que, nesse sentido, poderia ser valorizado, e mais criticamente continuado, o interessante trabalho de E. M. Theewen, Napoléons Antheil am Code Civil (1991), sobre o qual interviemos em outro lugar: Quaderni Fiorentini per la Storia del Pensiero Giuridico Moderno, n. 21, 1992, p. 585 e ss. 
adolescente', e de tornar culturalmente plausível uma colaboração entre as classes tendo em vista uma melhor preparação das futuras lutas ${ }^{5}$. Tal texto representa uma iniciativa que se inseria em um quadro mais amplo de 'revolução cultural'. A Libera Propaganda - uma associação de Torino que tinha entre os seus mais ativos dirigentes políticos e jornalistas liberais como Alessandro Borrella, Felice Govean, Agostino Depretis, este último, depois, chefe do primeiro governo da Esquerda - estava estreitamente vinculada ao jornal Gazzetta del Popolo e às suas campanhas progressistas e antirreacionárias: o Dicionário foi, conforme às suas intenções divulgativo-catequéticas, publicado fascículos (oito por mês, para um total de 256 páginas, forma característica de tantas edições 'populares' do séc. XIX, da almanaques à catecismos, inclusive laicos) a partir de janeiro de 1851, e o seu significado, nas intenções dos seus propugnadores, transcendia a sua materialidade 'livresca' - em outra assonância que não é somente curiosa com o caso que estamos contando - já que o verdadeiro 'grande livro' era, de fato, "o da liberdade e da vida política, que 1848 havia reaberto depois que, durante quase quarenta anos, fora trancafiado na arca da Santa Aliança”.

Mas, como foi argutamente notado pelos organizadores, ele constitui, ainda, um precioso auxílio para identificar, frequentemente na raiz, a estruturação de grande parte da linguagem politico-jurídica que ainda nos é familiar, bem como algumas das suas modalidades de constituição e atuação.

Em particular, a notável quantidade de neologismos específicos e de palavras que mantém o significante, mas sofrem uma sintomática mutação, total ou parcial, de significado, evidencia diretamente - na vivacidade, por assim dizer, da restituição do uso ou já 'popular' ou em vias de 'popularização' - uma larga circulação dessas palavras-ideia, que é, muitas vezes, imprevisivelmente antecipada em relação ao que nos ensinam os vocabulários históricos e etimológicos mais consultados.

Além disso, da experiência que se extrai da leitura, do fervilhar e da afirmação, naqueles anos decisivos da nossa história recente, de muitas palavras e ideias que chegaram íntegras até nos, conseguimos extrair também, para além do vício com o qual às vezes repetimos à exaustão a lição salutar e capaz de produzir estranhamento de uma consciência finalmente alcançada: aquelas expressões, longe de constituir um patrimônio perene, eram, em verdade, ao menos no uso 'comum', até ontem, “desconhecidas, estranhas à dotação linguística dos italianos”.

Leiamos, então, sub voce, dando a palavra ao original: “Código Coletânea de leis. Existe o código civil, o penal, o de comércio, que contém coletâneas de leis civis, criminais, comerciais, etc. O Código Napoleão é aquele

5 Dizionario politico popolare, Pietro Trifone (a cura di), Introduzione di Luca Serianni (Roma 1984) p. 66.

6 Cfr. L. SERIANNI, Introduzione, cit., p. 9. 
por ele promulgado, uma grande obra para a qual colaboraram os mais competentes jurisconsultos franceses, e na qual se modelaram [si modellarono], em seguida, quase todos os outros códigos da Europa".

A 'grande obra' representa, então, um 'modelo'. Ou melhor, podemos antecipar que essa noção tornar-se-á constitutiva do arquétipo interpretativo liberal-progressista (em seguida, eventualmente, inclusive na versão democrática).

Pelo que nos consta, porém, não houve, até hoje, uma análise históricotextual detalhada sobre como se chegou a essa específica e, certamente, nada 'inocente' formulação.

De nossa parte, temos que nos limitar a trazer somente mais um pequeno indício para um percurso que mereceria um aprofundamento bem maior.

Queremos nos referir às interessantes observações de Hortensius SaintAlbin (que é qualificado pelos editores como 'député'), contidas em um texto de gênero análogo, o Dictionnaire politique. Encyclopédie du langage et de la science poitiques, rédigé par une reunion de députés, de publicistes et de Journalistes, avec une Introduction par Garnier-Page (Paris, 1842): um dicionário interessante também por outros motivos, dada a perspectiva e, sobretudo, a estatura intelectual de alguns dos colaboradores (de Louis Blanc, F. Lamennais, a Leopardi - ? sic -, ao General Pepe, a Elias Regnault, etc.).

No verbete Code - mesmo preocupando-se principalmente em delinear as razões e as condições necessárias para colocar ao lado do código civil um Código político

Si le Code civil a révélé et accompli une haute pensée politique, peut-on en dire autant de ces innombrables lois et de tous ces décrets prétendus politique que nous avont reçus de l'Empire,de la Restauration, et de ce que nous appelons l'établissement de Juillet? Pourqoi la France attend-elle encore un Code politique? Quelles sont les causes de ce retard? L'Empire était dans l'impuissance de rédiger un Code politique. Tout étant soumis au despotisme et aux caprices du maître, la France étant tout entière armée, la gloire tenat lieu de tout le reste, l'Empire ne pouvait donner d'institutions au pays; conquérir au dehors ,opprimer au dedans, museler la liberté de la presse et toutes les libertés, régner avec un Sènat muet, tel fut le rôle de l'Empereur. Alors que la guerre était européenne, on ne pouvait songer qu'à la guerre et aux victoires: combattre et vaincre, voilà quel était l'esprit public

- nota, em primeiro lugar, a conexão entre a palavra e o processo de civilização ("Le mot Code implique une idée d'avancement chez le peuples: c'est l'ordre qui succède à la confusion, la civilisation a la barbarie"): conexão que, na Itália, é notoriamente típica, por exemplo, do pensamento de um Romagnosi e, como veremos em seguida, retomada de bom grado e com interesse por toda a classe dirigente risorgimentale.

Mas, sobretudo, e com uma consciência precisa assinalada pelo cursivo original no texto: 
Notre Code civil, sans en excepter le Code prussien, qui est aussi un Code modèle, est certaiment le premier de l'Europe et du monde; la plupart des états et même les états despotiques en ont adopté les dispositions. On peut dire de lui que, comme les trois couleurs, à l'ombre desquelles il à été inauguré, il fera le tour de l'univers.

O Código de Napoleão, portanto, é o Código-Modelo por excelência.

Tal excelência deve ser reconectada com lucidez - com um movimento interpretativo que lembra as páginas igualmente lúcidas sobre a necessária secularização como premissa real da ideia moderna de código de um jurista como Laurent ${ }^{7}$ - a um au-delà do texto político, a uma história violenta de 'anulação', a uma tabula rasa capaz de racionalizar, concentrar e mobilizar as forças do Estado-Nação; em uma palavra, a um verdadeiro plusvalor políticosimbólico que, em uma extensão algo paroxística da ideia de progresso, ultrapassa, inclusive, a síntese temporal de passado-presente para conjugar-se com o futuro:

Il n'y avait que le concours de toutes les volontés nationales, il n'y avait que la Révolution française elle-même qui fût capable d'anéantir l'hydre des coutumes; elle seule pouvait tout niveler, elle seule puovait et devait créer un Code. Elle avait posé le principe de l'égalité des droit entre tous les hommes réunis en corps de nation: il devait donc y avoir et il y eut table rase des coutumes comme de tous les abus; un nouveau régime politique ,uniforme pour tous les citoyens, devait produire l'unité de la législation. La réforme des mœurs devait amener a la réforme des lois. Il est donc juste de dire que la Révolution, par l'abolition des droits féodaux, peut être considérée comme ayant, la première, préparé un véritable Code des Français. L'Assemblée constituante, la Législative, en reconnurent l'utilité et le principe, et la constitution de 91 annonça un Code de lois nouvelles: elle prononça même le nom de Code civil, qu'on pourrait appeler Code du droit des citoyens ou de la cité. La Convention nationale entreprit l'œuvre, et allait le réaliser; le Directoire continua sans achever; l'Empereur Napoléon vint pour recueillir ce que la Révolution avait semé (...). Ainsi, l’appréciation du Code civil rentre particulièrement dans le cadre du Dictionnaire Politique, car ses auteurs furent animés d'une pensée éminemment politique. C'est le Code civil qui a établi la division des propriétés, qui a substitué le règne de l'égalité à celui du privilège. Il n'a pas détruit, il a renoue la chaîne des temps en empruntant aux anciennes lois ce qu'elles avaient de sain et d'utile, en collationnant, qu'on nous permette le terme, le passée, le présent, et, sous certains rapports, l'avenir.

O Code Napoleon, então, é o Código-Modelo por excelência porque é dotado de um plusvalor político (revolucionário, isto é, 'moderno’: por isso é também, em uma relação inovadora específica com a dimensão temporal, um

7 F. LAURENT (1810-1887), Principii di diritto civile, $1^{\text {a }}$ traduzione italiana dell'avv. Giuseppe Trono (Napoli 1879 vol. I), sobre o qual nos ocupamos em outra ocasião (Codici in M. FIORAVANTI,[a cura di], Lo Stato moderno in Europa. Istituzioni e diritto [Roma-Bari 2002]). 
'Código eterno', como já observávamos em Il codice eterno. La forma codice e i suoi destinatari: morfologie e metamorfosi di un paradigma della modernità ${ }^{8}$ ).

Esta verdadeira estrutura mental de carater simbólico (como disse muito bem Pierre Bourdieu, "la codification est une opération de mise en ordre symbolique, ou de maintien de l'ordre symbolique, qui incombe le plus souvent aux grandes bureaucraties d'État", a qual tem a ver "avec la discipline et avec la normalisation des pratiques" já que "les systèmes symboliques 'enrégimentent' ce qu'ils codifient" ${ }^{\text {") }}$ reproduziu-se e foi 'produtiva'.

Não por acaso, inclusive linguisticamente.

Mito e símbolo viajam, precisamente, em direção à Itália, por onde passou, certamente, também o 'modelo'. De fato, se voltamos agora, com a bagagem que acumulamos neste breve intervalo de discurso sobre a aparentemente inócua definição do dicionário 'popular', ao qual intencionalmente entrelaçamos nosso percurso, poderemos decifrar - agora, talvez, com menor surpresa, e, por outro lado, mais preparados para compreender a sua etiologia - um efeito mínimo, mas nem por isso menos significativo, da força configuradora, inclusive na linguagem, do novo campo semântico do nosso conceito e do nosso arquétipo.

O Código Napoleão, “aquele promulgado por ele”, é definido justamente como uma grande obra, e acrescenta-se: "sob o qual se modelaram [si modellarono], em seguida, quase todos os outros códigos da Europa” (e não só, mas também, complementemos, fora da Europa, e, em particular, na América Latina). Pois então, ao que parece, com aquele se modelaram estamos diante, na língua italiana, "à primeira atestação conhecida de modelar-se [modellarsi] no sentido de conformar-se" e não no sentido ativo da ação de configurar algo (o escultor que modela um torso $)^{10}$.

Se quisermos entrar um pequeno jogo de cruzamentos semânticos: a 'escrita' napoleônica que 'modela' a língua italiana.

Um pequeno 'sintoma' de uma 'grande' história.

\section{2.}

Ora, um modelo mítico, acima de tudo, é utilizável. A sua utilidade, todavia, é subtraída à discussão: um modelo não se discute.

Antes de qualquer coisa, deve ser executado, aplicado; ou melhor, agora já sabemos, devemos nos conformar a ele. E justamente esse 'conformismo' (progressivo) caracterizou, deve-se acrescentar, conscientemente, o comportamento da classe dirigente liberal.

8 In P. CAPPELLINI, B. SORDI, Codici. Una riflessione di fine millennio (Milano 2002) p. 11 ss.

9 P. BOURDIEU, Habitus, code et codification, in Actes de la recherche en sciences sociales, 64, 1986. p. 41.

10 P. TRIFONE, Dizionario, cit., p. 66, nt. 47. 
Um conformismo - conforme notava, por sua vez, Adriano Cavanna, amigo vivo nos nossos corações e, infelizmente, com doloroso pesar - em parte espontâneo, em parte fruto da sedução e instrumentalização do poder napoleônico em relação aos juristas.

Mas sempre baseado, de maneira equívoca, em uma mitificação, exatamente, 'modelizadora': aquela que via no Código Napoleão não o fruto da reação termidoriana e o instrumento decisivo do cesarismo bonapartista, mas o produto imediato dos imortais princípios de 1789.

Então, encontra perfeita confirmação, inclusive para a esfera jurídica, a substancial correção da intuição gramsciana expressa em uma rápida nota de Letteratura e vita nazionale.

O fato de boa parte da vida intelectual italiana até 1900, pelo menos nas suas correntes liberal-progressistas e, depois, 'democráticas', ser

simplesmente um reflexo francês, que teve origem na revolução de 1789: a artificialidade desta vida está (porém) no fato de que, na Itália, não houve as premissas históricas que, ao contrario, existiram na França. Nada de parecido, na Itália, à revolução de 1789 e às lutas que seguiram a ela; todavia, na Itália, 'falava-se' como se tais premissas tivessem existido....

O “símbolo de uma palingênese emancipadora” radicada na península por uma sapiente estratégia cultural e política de "desnacionalização" do pensamento jurídico torna-se, assim, paradoxalmente, 'palavra de ordem' e um dos símbolos do Risorgimento: "Viva a Itália, viva Vittorio Emanuele, viva o código Napoleão" (palavras do deputado toscano Montanelli em 1859).

Em suma, e mais uma vez na felicíssima formulação de Cavanna: “O código civil francês deve ser considerado, então, por mais paradoxal ou urticante que possa parecer, como um dos fatores genéticos fundamentais da identidade nacional italiana" 11 .

Muitos aspectos poderiam ser colocados em evidência, todos, de alguma forma, vinculados ao caráter de artificialidade de fundo assinalado acima.

Por razões naturais de economia discursiva, a nós urge assinalar ou precisar dois em especial.

Partamos, para o primeiro, da estratégia retórica empregada por um dos protagonistas da unificação legislativa risorgimentale, Giovan Battista Cassinis, que foi, desde 20 de janeiro de 1860, ministro de Graça e Justiça no governo Cavour, e cujo “projeto de revisão de 1860, para o bem o para o mal, é já o código de 1865"; estratégia recentemente argutamente focalizada no belo volume de S. Solimano, não por acaso um dos melhores alunos e seguidores do magistério de Cavanna ${ }^{12}$.

11 A. CAVANNA, Miti e destini del Code Napoléon in Italia, in Europa e diritto privato, 2001,1, p. 100 .

12 S. SOlIMANO, "Il letto di Procuste". Diritto e politica nella formazione del codice civile 
Cassinis não deixava de conectar o código civil com o processo de revigoramento e civilização nacional e de exaltar o altíssimo valor simbólico de tal meta:

Quando uma nação, recolhidos os membros esparsos, se recompõe em Estado uno e independente, a sua primeira necessidade é externar-se na sua nova existência, reduzindo-a em ato, e confortar a unidade do Estado com a unidade das leis (...) se o valor italiano vive e tantas obras fez nos sanguinários campos de Palestro e de San Martino, a Itália, fornecida ainda de sapiência civil, sabe igualmente fazer as suas leis como soube fazer as suas batalhas.

O objetivo de imitação é (napoleonicamente) claro (força das armas versus força das leis): e é finalmente alcançado inclusive em um aspecto simbólico absolutamente relevante.

A unidade política conquistada, com a proclamação do Reino da Itália, fará com que o código civil, também para os olhos dos juristas italianos, fique cheio do forte significado simbólico estreitamente conexo a um plusvalor político que, agora, já nos é familiar: ainda que, dessa vez, mais do que pela alegada componente da premissa revolucionária, mas pela da consolidação nacionalista.

Ela representa, de fato, "o emblema da liberdade alcançada”, mas, "ao mesmo tempo, o selo da unidade política essencial para consolidar o 'peso' da nação em construção diante das Potências europeias. Ela deve ser realizada, portanto, a qualquer custo e o mais rapidamente possível. As razões da política esmagam as do direito" 13 .

O código civil torna-se, então, uma instituição-chave, de modo a garantir a homogeneidade, e, assim, a 'credibilidade' do jovem Estado-potência em relação aos seus 'pares' no fórum da Europa moderna.

A consideração, certamente, não deve surpreender ou parecer arriscada, basta que se pense que tais reflexões sobre 'racionalização de Estado' serão replicadas no mais alto nível para fazer 'passar', em 1917, a aceitação da formacódigo até para o direito canônico ${ }^{14}$.

Se era politicamente imprescindível chegar logo em um código, acelerar ao máximo o processo de unificação legislativa, proceder, em suma, àquilo que ficou conhecido sob o nome eficaz de "unificação a vapor”, a estrada mais óbvia era, então, a de levar a cabo os trabalhos já começados, aproveitando plenamente, porém, todas as valências do Código Napoleão como 'Code modèle', seguindo-o ainda mais de perto. E é precisamente isso o que foi feito.

unitario. I Progetti Cassinis 1860-1861, Milano, 2003.

13 S. SOLIMANO, "Il letto di Procuste". Diritto e politica nella formazione del codice civile unitario. I Progetti Cassinis 1860-1861, Milano, 2003.

14 C. FANTAPPIÉ, Chiesa romana e modernità giuridica I-II (Milano 2008). 
Com quais consequências? Pressupondo que o estudo específico da 'história das codificações' alcançou somente em tempos não muito distantes (em torno do inicio dos anos 80) uma autonomia (ao lado da 'história das constituições'), poderíamos dizer que o filão que definiremos ‘ortodoxo' da historiografia jurídica italiana perscrutou a fundo as consequências positivas. Estamos nos referindo ao filão que opera em substancial, e, às vezes, ideologicamente explícita, adesão aos valores (iluministas-)liberais e risorgimentali como expressões particulares do mais amplo contexto de positividade que é representado pela modernidade (entre outros, Ghisalberti, Ascheri, Petronio).

Nessa ótica, os apontamentos críticos adquirem, quando presentes, um valor marginal (frequentemente sob o signo de argumentações do tipo "o quadro histórico geral não permitia agir de outra forma" ou similares) e, de qualquer forma, de modo a não afetar um balanço largamente positivo. Considerações críticas de teor mais estrutural representam exceções.

Pode-se tranquilamente afirmar que, mais recentemente, com o aparecimento de importantes posicionamentos que gostaríamos de definir não como simplesmente 'heterodoxas', mas como próprias de uma 'nouvelle histoire juridique', o quadro está se tornando fortemente diferenciado e variado.

Aludimos, como é claro, - desde o fim dos anos 80 - às numerosas intervenções de Paolo Grossi que, em síntese extrema, poderíamos caracterizar como uma colocação historiográfica das intuições de um dos pais do 'estranho' código civil de 1942, isto é, o Filippo Vassalli de Extrastatualità del diritto civile $(1951)^{15}$.

Tais intervenções, agora oportunamente recolhidas em um volume Assolutismo giuridico e diritto privato (Milano 1998) -, como se sabe, têm como propósito evidenciar o ‘absolutismo jurídico' como a cifra do desenvolvimento 'moderno' do culto do abstrato, da generalidade e da lei, especialmente na sua versão codificada. E identificar, por isso, como consequência necessária, uma série de frutos genuínos, mas nem por isso menos dotados de um valor também negativo, isto é, “a anulação do pluralismo jurídico, um vínculo não natural entre direito e poder político, uma verdadeira legolatria, uma completa desvitalização da ciência jurídica”.

Mas queremos aludir, também, e já o fizemos em parte, aos decisivos ensaios de revisão historiográfica que, exatamente sobre a temática do Código Napoleão, e, em vários aspectos, em autônoma sintonia com os resultados grossianos, escritos por Adriano Cavanna. E nos limitamos a assinalar aquele que é, talvez, desde o título, o mais 'programático': Miti e destini del Code Napoleon in Italia ${ }^{16}$.

15 In Scritti giuridici, tom. III, 1960.

16 In Europa e diritto privato , I, 2001, pp. 85-129, 125 nt. 164. 
Conectando-nos idealmente a essas perspectivas, parece-nos ser possível elucidar melhor o segundo aspecto que mencionamos. Um aspecto estritamente conexo à indiscutível prevalência das razões da política sobre as do direito na condução da unificação legislativa, e, portanto, vinculado também ao caráter de artificialidade da vida intelectual italiana, bem colocado pela análise gramsciana.

De fato, poder-se-ia afirmar - e já notava muito argutamente outro dos pais do nosso código civil de 1942, Rosario Nicolò (Codice civile, 1961) ${ }^{17}$ - que a consciência da exigência de unificação legislativa do direito privado das varias 'regiões' italianas e a convicção de que somente a conformação à codificaçãomodelo consentiria a rápida realização dela tiveram, ainda, um ulterior efeito decisivo no plano jurídico-cultural.

Elas funcionaram, não por acaso, como 'impedimento' contra um real "movimento de ideias sobre os problemas de fundo da codificação".

Em suma, se quiséssemos reduzir a questão a uma fórmula, mas a uma formula não simplificadora, mas o mais sintética possível, deveríamos dizer que o ‘modelo' funcionou como ‘obstáculo epistemológico' para que se discutisse, na Itália, o que significa realmente codificar, quais suas vantagens e seus custos.

Tudo isso é visível desde o princípio. No relatório Cassinis de junho de 1860 ao primeiro projeto de revisão do código albertino, já era evidente, de fato, qual estrada se pretendia tomar a esse propósito.

Nenhuma dúvida sobre a circunstância de que "a fórmula codificada do direito" seria incontrovertidamente "a vocação do século" e, sobretudo, que além de ser, obviamente, agora sabemos, "uma condição dos progressos civis”, "a questão do método de codificar já fora resolvida pelos fatos e pelo consenso universal".

Era absolutamente natural que, ainda mais explicitamente, a porta fosse trancafiada diante de um eventual debate no momento do abandono da ideia de revisão do código albertino, para passar a projetos mais próximos ao modelo napoleônico: sempre Cassinis, em um discurso na Câmara - é ainda Nicolò quem nos lembra -, afirmou, evitando equívocos, que não se tratava de "formar um código", mas somente de "compilá-lo".

A técnica dos trabalhos sucessivos (projetos Miglietti e Pisanelli) e a velocidade deles confirmam plenamente a tendência. Eles se caracterizaram, na prática, ainda, "pela preclusão, na última fase, de qualquer discussão em sede parlamentar, seja geral, seja particular, por força da autorização ao Governo (I. 2 de abril de 1865) para publicar e colocar em execução com simples decreto os códigos civil, de processo civil e para a marinha mercantil (e o código de comércio, segundo uma emenda integradora aprovada na discussão do projeto de lei) no estado em que se encontravam naquele momento os relativos projetos, salvo as emendas que o próprio Governo tinha o poder de aportar”.

17 In Scritti, vol. II, 1980. 
Em uma palavra, estamos diante não somente da prova cabal de que a questão foi encerrada antes mesmo de poder ser colocada na ordem do dia; mas, ainda, do fato de que a fórmula, que a muitos não agrada, do “absolutismo jurídico" é plena de um conteúdo histórico absolutamente específico.

Nesse sentido, não surpreenderá repetir a observação segundo a qual as circunstâncias descritas em linhas gerais "impediram que, na Itália, ganhassem consistência e vigor as polêmicas sobre a codificação".

Esse dado, certamente, não é pequeno na avaliação geral da contribuição da ciência jurídica italiana para o desenvolvimento do nosso direito civil moderno.

E nos parece um dever subscrever, novamente, a opinião expressa em outro lugar pelo advertido civilista, mesmo que ele não pudesse, ainda, remontar à genealogia de algumas expressões sintomaticamente (e historicamente, agora já sabemos, de modo absolutamente forte) utilizadas:

pode-se começar notando como a doutrina civilística italiana, que trabalhou nos anos imediatamente sucessivos à codificação, fez mais ou menos aquilo que os próprios compiladores do código civil tinham feito. Do mesmo modo que o nosso código civil modelou-se [si era modellato] no código francês, a nossa doutrina modelava-se [si modellava] na francesa, adotando os seus métodos de investigação e orientações aplicativas. A avaliação crítica da contribuição dessa doutrina que se limitava muito frequentemente à exegese das normas e se abstinha de construções conceituais, não pode, portanto, ser positiva. A repetição dos motivos caros à doutrina francesa, que, por sua vez, se colocava, sem uma tentativa apreciável de reelaboração original, na esteira dos grandes juristas que constituíram o suporte teórico do code Napoléon, não podia dar lugar a um movimento científico digno deste nome.

Com isso não se pretende esposar totalmente uma 'história possível', que nos empurraria, talvez, a substituir o 'modelar-se' até aqui descrito por outra e diferente (por exemplo, de matriz alemã) como 'historicamente melhor'. Não se trataria de retomar e aprofundar a polêmica na linha das exigências, por exemplo, da escola histórica: a aposta é que, onde o debate não tivesse sido sufocado e tivesse podido florescer e se desenvolver, a história seria ou poderia ter sido outra.

Para usar da profunda intuição, a nosso ver, de Alberto Aquarone, tratarse-ia, talvez, de evitar que, assim, fosse dada "origem a uma das muitas fraturas internas da sociedade italiana que tornariam difícil a vida do novo Estado pósrisorgimentale" 18 .

Que a ocasião propícia "para uma transformação em profundidade do direito civil" não fosse, como aconteceu, perdida.

Hoje, uma história da codificação na Itália que parta desta "ocasião perdida”, não por acaso, ainda está por ser escrita.

18 A. AQUARONE, L'unificazione legislativa e i codici del 1865, 1960, p. 80. 
Talvez, mesmo sem querer acreditar que a história seja magistra vitae, assim como hoje (na Europa, dessa vez), aquela polêmica teria merecido e mereceria ainda ser retomada.

Mas, em que sentido? Sigamos, pela última vez, o nosso atento guia nestas reflexões "incompletas".

Especificamente, aquela polêmica mereceria ser retomada para definir o que deve representar um código de direito privado em uma sociedade moderna, isto é, se ele deve ser um corpus, o mais completo possível, de normas precisas e analíticas para todos os institutos da vida jurídica, inspiradas no rigoroso tecnicismo dos iniciados, ou se deve ser um tecido de princípios, sobre os filões fundamentais da experiência jurídica que, pela sua capacidade expansiva e flexibilidade, possam, através da integração de fontes normativas de caráter menos formal do que um código (leis especiais, usos, etc.) e através do penetrante trabalho dos juristas, teóricos e práticos, que vivem e compreendem essa experiência, adequar-se mais de perto ao ritmo da evolução das nossas estruturas sociais.

Dois “au-delà du texte” parecem, em suma, confrontar-se para encontrar uma superior conciliação: o de Roland Barthes e aquele, mais antigo e, obviamente, mais conhecido pelos juristas, de Raymond Saleilles; o "estranho elogio demolidor” (Grossi) expressado exatamente em relação ao code: “audelà du texte, par le texte".

Talvez, porém, - é uma sensação nossa - tal conciliação poderia, ou poderá, desenvolver-se melhor acentuando, mais do que a dimensão simbólica do código, a dimensão simbólica do direito. 